\title{
Indirect biomass estimations in Collembola
}

Marian Caballero, Enrique Baquero, Arturo H. Ariño*, Rafael Jordana

Department of Zoology and Ecology, University of Navarra, E-31080 Pamplona, Spain

*Corresponding author.

E-mail address: artarip@unav.es (A.H. Ariño)

\section{SUMMARY}

We propose coefficients for regressions relating dry weight to body or tergite length in Folsomia candida, Entomobrya schoetti, Sminthurus viridis, and Hypogastrura vernalis (Collembola). Measurements were made on large batches of preserved, identified specimens. Batches were dessicated completely by critical-point drying and weighed. We compare our data with other published models and critically review the literature, finding questionable records.

\section{KEYWORDS}

Biomass estimation; Collembola; Length-weight regressions 


\section{INTRODUCTION}

It has been long established that the estimation of standing crop is fundamental in studies of population and community ecology and production biology (Petersen, 1975). Many ecological measures, such as soil respiration, net production and litter turnover rates, are to be explained in terms of soil fauna activity including Collembola, which in turn requires precise measurements of its biomass (Dunger, 1968; Persson and Lohm, 1977; Petersen, 1994, 1995, 2000; Detsis, 2000).

Recently, there is increasing interest on the use of biomass when estimating biodiversity (Jordana et al., 2000), as opposed to (or complementary of) the widespread use of specimen numbers. Size differences between individuals or species may bias the use of diversity as an assessment tool for the "status" of an ecosystem. Small individuals, of correspondingly small effect on the ecosystem, are assigned an unrealistically large role by equaling them with large ones, thus violating the basic tenet of "equal differences" for the concept of diversity (Krebs, 1999). Biomass can be regarded as a homogenizer for diversity measures, once these are corrected for continuous variables.

For small soil animals, direct measurement of the biomass of samples is often difficult due to their minute size, large numbers, and triage procedures. Thus, research has been published attempting to relate easier, more reliable measurements, such as length, to biomass. Allometry has been used to relate, by least-squares regression, the biomass to a lower dimensional measure, typically body length or width, through a power function or otherwise. However, many of these papers (i.e. Huhta and Koskenniemi, 1975; Schatz, 1981; Ganihar, 1997) deal with complex groups, such as "Collembola", which has a wide range of sizes and shapes. The goal of homogenizing counts through biomass for biodiversity studies requires good biomass estimates on a species-by-species basis.

According to Petersen (1975), the first paper dealing with specific biomass estimates for Collem-bola was that of Tanaka (1970) for some Japanese springtails, for which the coefficients for a log-log regression between body length and weight were given. Previously, Edwards (1967) had published equations based on cubic regressions for families of Collembola. Petersen's (1975) work is widely cited, containing also log-log equations similar to Tanaka's. Later, Van Straalen (1989) published parabolic curves for two species of Tomoceridae, and Teuben and Smidt (1992) added some more log-log curves.

Other information may exist as tables or unpublished data. Fjellberg (1975) referred to unpublished data on body size/weight relationship for Collembola populations on Hardangervida. Vannier $(1973,1977 b$, c) published individual series of data for some large Entomobridae.

The aim of this research was to add new species or populations to the set of groups of Collembola for which adequate regressions relating weight to body length are known, and to investigate whether these equations yield consistent results. We measured different lengths on individual Collembola, and performed regressions against their dry weight after grouping the animals by similar sizes. After studying the behaviour of the models, we chose one particular length for each of four species to be used as estimator for the dry weight of the individual. 


\section{MATERIALS AND METHODS}

\section{Sampling of Collembola}

Four species were selected as representative of their groups. Folsomia candida was reared in the laboratory in large numbers. A very large sample of a population of Hypogastrura vernalis was collected from the surface of a swimming pool in Labiano (Navarra) in 2000. Entomobrya schoetti and Sminthurus viridis were collected in large numbers from an alfalfa (lucerne) field in Navarra where they had become a pest, in 1997.

\section{Preparation and measurements}

The animals were preserved in $70 \%$ ethanol. The length of a straight line between the anal papillae and the front margin of the first thoracic segment (in all species but E. schoetti); the length of the fourth abdominal segment (in E. schoetti); the total length excluding antennae (in S. viridis); and the length of the straight line between the posterior margin of the head and the base of the antennae, or the end of the labrum in $\mathrm{S}$. viridis, were measured, placing the specimens on their side under a stereomicroscope, by a pre-tabulated eyepiece micrometer. Animals were grouped by size classes so as to obtain up to 10 different, homogeneous classes, which were then subject, batch by batch, to dessication by critical point drying with liquid carbon dioxide. Shape and size were thus subsequently fully retained. In order to avoid rehydratation, dried specimens were kept at all times in dessicators with silicagel. Size batches, each containing 30-300 specimens of one species, were weighed repeatedly with a one-microgram microbalance $(10 \mu \mathrm{m}$ scale for E. schoetti).

\section{Data analysis}

The ratio between head length and body length, or between head length and body length excluding head, was established by least-squares regressions. Results of this analysis were used to determine which length to use for the regressions between length and weight. We chose the measure having the largest intrinsic variation (i.e. largest coefficient of variation) to separate between classes. Precision factors for the measurements were obtained by dividing the unit length by the range for each measurement.

The regressions were calculated assuming a power function of the type $\mathrm{W}=\alpha \mathrm{L}^{\mathrm{b}}$, where $\mathrm{L}$ is a linear length $(\mathrm{mm})$ and $\mathrm{W}$ the weight (micrograms). We used the average length of the body excluding the head (or the abdominal segment IV in E. schoetti), measured as described above, plotted against the last weighing before rehydratation would take place for the batch. Although other, slightly better fitting functions (mostly polynomial) were tested through the use of mathematical software (Tablecurve v. 2.12), for the sake of homogeneity and comparability we chose to stick to this most commonly used allometric function.

In order to find agreement between our data and published coefficients, we plotted our functions together with the published functions. In case they described the relationship 
between length and fresh weight, the function was corrected using published fresh weight to dry weight ratios for the corresponding family. However, in many cases comparisons were not possible, as the lengths used for the regressions were measured differently among studies and there could not be set a homogeneous "unit length" for all species. Where this was possible, a "unit type" (i.e. the weight of an animal measuring one unit in length) was also used for comparison among species and groups. A quick quality check was performed on the coefficients to discard obvious errors by calculating the minimal density of a unit sphere according to the regression coefficients. No correction was included for "swelling factor", as they have been found to be poorly documented.

\section{RESULTS}

A total of 4061 specimens were measured. The achieved precision for the length measurements was $16 \mu \mathrm{m}$ for the measurements in $\mathrm{H}$. vernalis (precision $1.1 \%$ for body length) and E. schoetti (precision 3.1\%), and $24 \mu \mathrm{m}$ for S. viridis (precision 1.3\%) and F. candida (precision $1.7 \%$ for length of abdominal IV).

We chose the measure that maximized the measure range for the whole group (i.e. that of maximal $\mathrm{CV}$ ) in order to set up as many classes as feasible for the weighing (Table 1). Therefore, we used the length of the body without head except for E. schoetti, where we used the abdominal segment IV, for subsequent analyses.

All species fit well within a power function, with different coefficients for each species (Fig. 1). All our data fit within the published biomass ranges for their corresponding groups of Collembola. However, taking into account that for a given length we must obtain a weight slightly higher than that obtained from regressions where total length was used, it is surprising that our curves fall just about or slightly below the corresponding published weights (Fig. 1). This affects both the regression curve and the actual data. Comparisons of E. schoetti with published data were not possible since we were unable to find regression data of head length vs. weight for Entomobrya.

\section{DISCUSSION}

Our results are in range with published data and regressions (Fig. 1 and Table 2), with some exceptions. This is somewhat surprising, since we were not using total lengths but a fraction (i.e. body without head, or just the length of abdominal segment IV for E. schoetti) whereas other authors used total length, or length without head for Entomobryidae (where we measured just one segment). The calculated dry weight per unit length was expected to be higher for our animals, accounting for the weight of the remaining part of the body. As indicated in Table 2, the drying methods varied among the studies, and no two studies used the same drying procedure before weighing; Edwards (1967) and Van Straalen (1989) reported their equations for fresh weight although a correction factor is given in Table 2 for comparison. It should be noted, however, that the water content in Collembola is highly variable and depends on the degree of starvation, ambient conditions, transportation conditions and catching procedures (Vannier, 1976, 1977a; Thibaud and Vannier, 1978; Vannier and Verhoef, 1978; Petersen and Luxton, 1982). 
Differences in body weight estimations from linear measurements, all things being equal, should be related solely with the material density or the aspect factor (i.e. the degree to which the shape differs from a regular, equal shape). Thus, more slender bodies should correlate to smaller volumes for unit length, and more globular ones to greater volumes (Fig. 2). Shapes for a given species should be similar; therefore, only density is left to account for differences. Our drying procedure used (critical point drying by phase change of liquid $\mathrm{CO}_{2}$, a procedure commonly used in electron microscopy to ensure complete removal of water without any volume or shape loss), together with our use of preserved specimens, has rendered dry materials which are somewhat "drier", or lighter, than that obtained by other drying procedures such as freeze drying drying in an oven. Vannier (1976) and Thibaud and Vannier (1978) have reported fat contents of Collembola tissue and, although they were comparatively low, they may affect dry weight measurements. Teuben and Smidt (1992) reported as much as $15 \%$ loss of dry matter after storage in preservative fluids for 3 weeks.

Other discrepancies may stem from typographic errors on published data. Some of the coefficients published in Teuben and Smidt (1992) are mistaken. If true, a $1 \mathrm{~mm}$ long Hypogastrura would have a dry weight of $5.5 \times 10^{6} \mu \mathrm{g}$ : its lowest possible specific gravity, were it perfectly spherical, would be over one thousand, that is, almost fifty times heavier than the heaviest element (iridium). Likewise, the coefficients for Isotoma notabilis and Orchesella cincta in this paper cannot be used as they are. It seems also that Teuben and Smidt did indeed obtain correct estimates for the coefficients, as results in the same paper based on these coefficients appear to be reasonable and do not reflect these errors; however, a number of papers may have used the published equations for biomass calculations (e.g. Detsis, 2000). We have not found a correction for these estimates, although it is likely that it might exist in the literature. As regards to the parabolic equation in Van Straalen (1989), the third term should be read " $a_{2}(\log Y)^{2}$,, (Van Straalen, pers. comm.)

The range of differences in weight per unit length of Collembola found in the reported literature (see Fig. 2 for Arthropleona) suggest that the estimation of biomass from length measurements varies with the procedure used for the calculation of the regression curves. Thus, we conclude that precise figures for the dry weight of Collembola are yet to be published, much as they are needed for respiration or biodiversity studies. Our data, based on a large number of measurements, added figures for a few common species; more such studies are necessary for a more complete analysis of the structure and function of Collembola communities.

\section{REFERENCES}

- Detsis, V., 2000. Vertical distribution of Collembola in deciduous forests under mediterranean climatic conditions. Bel. J. Zool. 130 (Suppl. 1), 55-59.

- Dunger, W., 1968. Die Entwicklung der Bodenfauna auf rekultivierten Kippen und Halden des Braunkohlentagebaues. Abhand. Ber. Naturkundmus. Görlitz 43 (2), 1256.

- Edwards, C.A., 1967. Relationship between weights, volumes and numbers of soil animals. In: Graff, O., Satchell, J.E. (Eds.), Progress in Soil Biology. Friedr. Vieweg ft Sohn GmbH, Braunschweig, pp. 585-591. 
- Fjellberg, A., 1975. Organization and dynamics of Collembola populations on Hardangervidda. In: Wielgolaski F.E. (Ed.), Ecological Studies Analysis and Synthesis, vol. 17, Fennoscandian Tundra Ecosystems, Part 2, pp. 73-79.

- Ganihar, S.R., 1997. Biomass estimates of terrestrial arthropods based on body length. J. Biosci. 22, 219-224.

- Huhta, V., Koskenniemi, A., 1975. Numbers, biomass and community respiration of soil invertebrates in spruce forest at two latitudes in Finland. Ann. Zool. Fennici 12, 164-182.

- Jordana, R., Arpin P., Vinciguerra, M.T., González, S., Aramburu, M.P., Ariño, A.H., Armendáriz, I., Belascoáin, C., Cifuentes, P., Clausi, M., Escribano, R., García Abril, A., García-Mina, J.M., Hernández, M., Imaz, A., Moraza, M.L., Ponge, J.F., Puig, J., Ramos, A., 2000. Biodiversity across ecotones in desertificable Mediterranean areas. In: Balabanis, P., Peter, D., Ghazi, A., Tsogas M. (Eds.), Mediterranean Desertification Research Results and Policy Implications, vol 2. European Comission EUR 19303, pp. 497-505.

- Krebs, C.J., 1999. Ecological Methodology, second edition. Addison Wesley Longman.

- Persson, T., Lohm, U., 1977. Energetical significance of the Annelids and Arthropods in a Swedish Grassland Soil. Ecol. Bull. 23.

- Petersen, H., 1975. Estimation of dry weight, fresh weight, and calorific content of various Collembolan species. Pedobiologia 15, 222-243.

- Petersen, H., 1994. A review of collembolan ecology in ecosystem context. Acta Zool. Fenn. 195, 111-118.

- Petersen, H., 1995. Energy flow and trophic relations in soil communities: state of knowledge two decades after the international biological programme. In: Edwards, C.A., Abe, T., Striganova, B.R. (Eds.), Structure and Function of Soil Communities. Kyoto University Press, pp. 111-130.

- Petersen, H., 2000. Collembola populations in an organic crop rotation: population dynamics and metabolism after conversion from clover-grass ley to spring barley. Proceedings of the Vth International Seminar on Apterygota, Córdoba 1998. Pedobiologia 44, 502-515.

- Petersen, H., Luxton, M., 1982. A comparative analysis of soil fauna populations and their role in descomposition processes. Oikos 39, 288-388.

- Schatz, H., 1981. Abundanz, Biomasse und Respirationsrate der ArthropodenMesofauna im Hochgebirge (Obergurgl, Tiroler Zentralalpen). Pedobiologia 22, 5270.

- Tanaka, M., 1970. Ecological studies on communities of soil Collembola in Mt. Sobo, Southwest Japan. Jap. J. Ecol. 20, 102-110.

- Teuben, A., Smidt, G.R.B., 1992. Soil arthropod numbers and biomass in two pine forest on different soils, related to functional groups. Pedobiologia 36, 79-89.

- Thibaud, J.M., Vannier, G., 1978. Rélations entre les tailles, les biomasses, les teneurs en eau et en lipides chez deux espèces de Collemboles selon leur répartition dans la grotte de Sainte-Catherine (Ariège, France). Rev. Ecol. Biol. Sol 15, 89-101.

- Van Straalen, N.M., 1989. Production and biomass turn-over in two populations of forest floor Collembola. Neth. J. Zool. 39, 156-168.

- Vannier, G., 1973. Relations dimensionnellement homogenes entre la taille, la surface et le poids des individus de l'espèce Allacma fusca (L.). Insecte Collembole. Rev. Ecol. Biol. Sol 10, 559-573. 
- Vannier, G., 1976. Évolution de l'équation linéaire entre poids frais et poids secs corporels dans une même population entomologique pendant une periode de forte evaporation. C.R. Acad. Sci. Ser. D 282.

- Vannier, G., 1977a. New proposal for calculating the average bodily water contents independent of the number of individuals in a soil population sampled weekly throughout a year. Rev. Ecol. Biol. Sol 14, 321-324.

- Vannier, G., 1977b. Relations hydriques chez deux espèces de Tomoceridae (Insectes Collemboles) peuplant des niveaux écologiques séparés. Bull. Soc. Zool. Fr. 102, 63-79.

- Vannier, G., 1977c. Water relationships in two species of Tomoceridae (Insecta, Collembola), a cave dwelling species and a top soil layer species. Rev. Ecol. Biol. Sol 14, 31-35.

- Vannier, G., Verhoef, H., 1978. Effect of starvation on transpiration and water content in the populations of two co-existing collembola species. Comp. Biochem. Physiol. 60a, 483-489. 
Table 1. Mean lengths and range of lengths (in $\mu \mathrm{m}$ ) of head, body, abdominal segment IV or body without head of the specimens

\begin{tabular}{|c|c|c|c|c|c|c|c|}
\hline Species & $\mathbf{N}$ & Measurement & Mean & Range & $\mathbf{C V}$ & Precision (\%) & Classes \\
\hline \multirow{2}{*}{ H. vernalis } & 635 & Head & 131.7 & $82-197$ & 0.188 & 14.3 & 8 \\
\hline & & Body excl. head & 797.1 & $393-1229$ & 0.231 & 2.0 & \\
\hline \multirow[t]{2}{*}{ F. candida } & 750 & Head & 140.9 & $73-340$ & 0.459 & 9.1 & 6 \\
\hline & & Body excl. head & 685.6 & $242-1673$ & 0.563 & 1.7 & \\
\hline \multirow[t]{2}{*}{ E. schoetti } & 741 & Head & 193.0 & $82-377$ & 0.384 & 5.6 & 10 \\
\hline & & Abdominal IV & 303.7 & $98-623$ & 0.481 & 3.1 & \\
\hline \multirow{3}{*}{ S. viridis } & 1935 & Head & 493.5 & $244-1292$ & 0.460 & 2.3 & 8 \\
\hline & & Body excl. head & 700.6 & $268-2195$ & 0.593 & 1.3 & \\
\hline & & Body total & 836.5 & $341-2731$ & 0.578 & 1.0 & \\
\hline $\mathrm{N}=\mathrm{nu}$ & cot & into which & i not & $\begin{array}{l}\text { iation. } \\
\text { group }\end{array}$ & es & $\begin{array}{l}\text { e number of si } \\
\text { g. }\end{array}$ & \\
\hline
\end{tabular}


Table 2. Published equations and coefficients for the relatiorship between body length and body weight

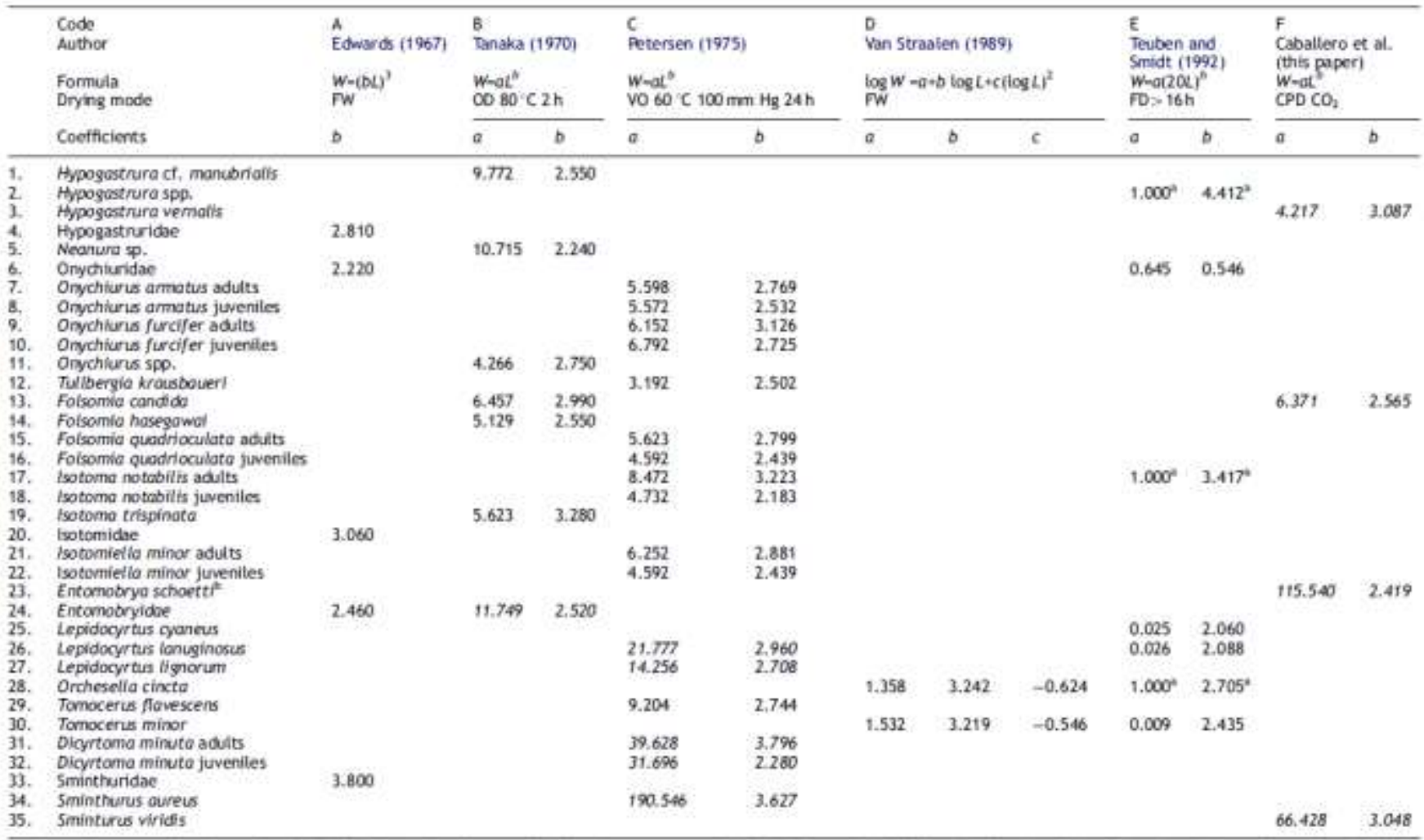

Author and taxon codes refer to Flg 3. FW: fresh weight; OO: oven dred; vo: vecuum-oven dried; FD: freeze dried; CPD: Gitical point drying: Flgures in itafics apply to length of body exduding head.

Unrealistic data.

thength of Abd. IV only. 

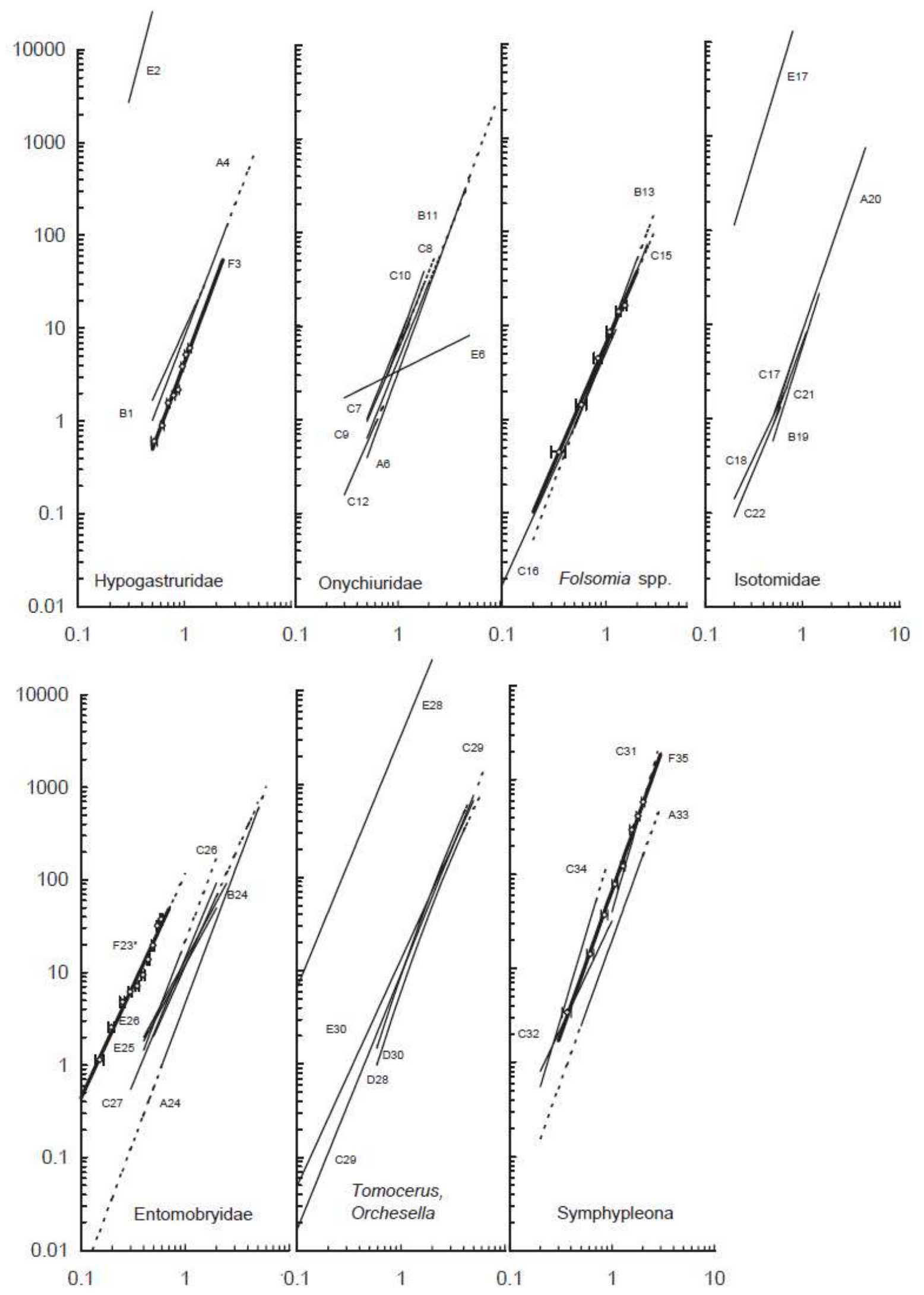

Figure 1. Dry weight-length regression lines from literature (thin) and this work (thick, with error bars). Solid lines indicate the range for which the regression was defined; dotted lines indicate the size range for the taxon. Codes indicate author (A-F, from Edwards, 1972 to Caballero et al.) and taxon (number) as seen in Table 2. F23 (E. schoetti, this work) based on length of abdominal segment IV only. 


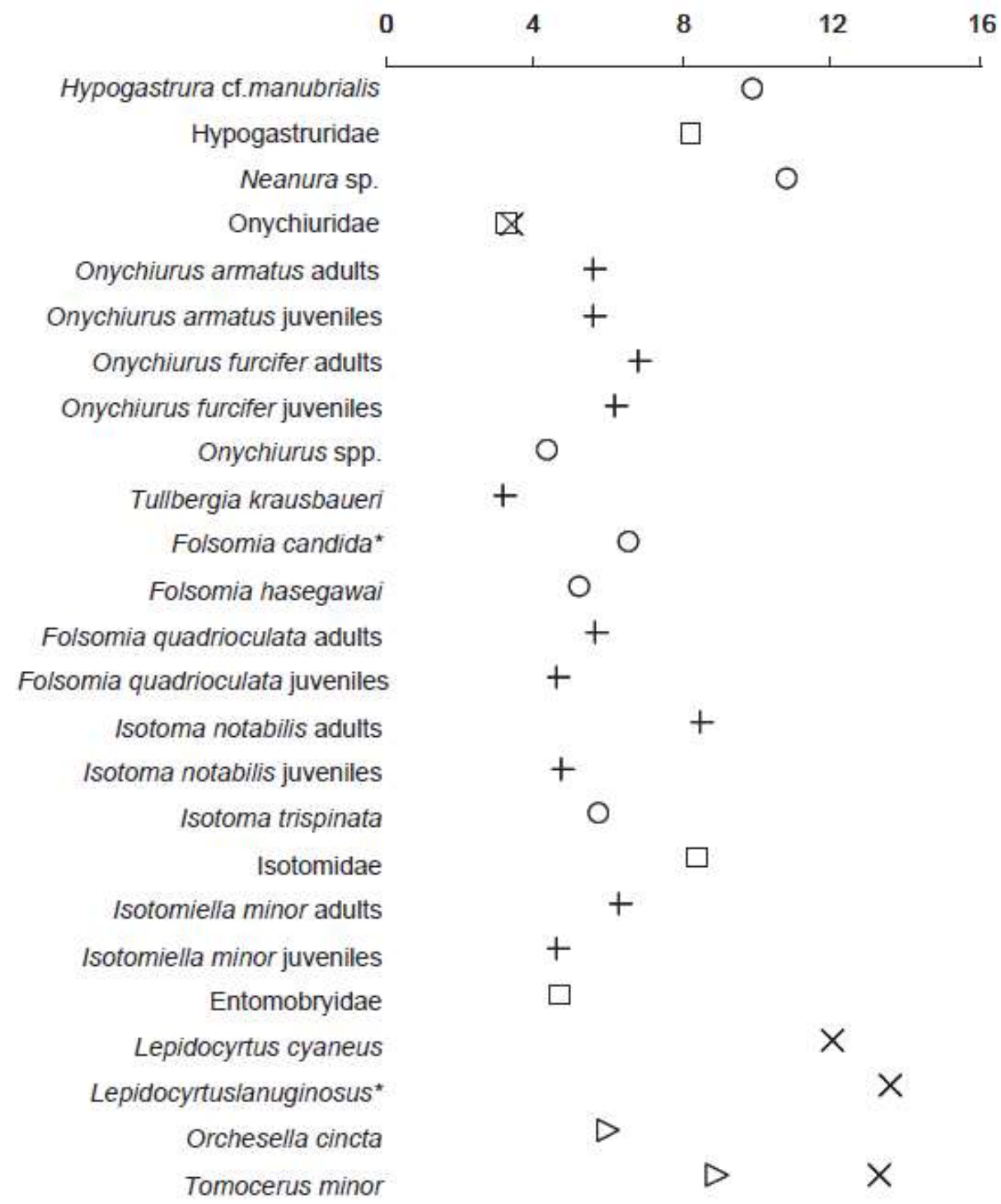

Figure 2. Weight (in micrograms) of specimens of Arthropleona measuring $1 \mathrm{~mm}$ (total body length) calculated according to Edwards (1967, squares); Tanaka (1970, circles); Petersen (1975, crosses); Van Straalen (1989, triangles); Teuben and Smidt (1992, X symbol). 